\title{
Investigation of Thermophysical Properties of Nanofluids and Effects of MHD
}

\author{
Elif Büyük Öğüt ${ }^{1} \quad$ Seda Dilki ${ }^{2}$ * \\ 1. Vocational School of Hereke, Kocaeli University, 41800 Hereke, Kocaeli, Turkey \\ 2. Kocaeli University, Institute of Science, Kocaeli, Turkey
}

\begin{abstract}
Heat transfer through a fluid; It is an important parameter in many engineering fields such as heat exchangers, solar collectors, refrigerators, automobiles, cooling of electronic devices, power plants. The increasing demand for energy has made it necessary to use energy more efficiently. For this purpose, it is necessary to design compact, low-cost systems with high thermal conductivity and high-performance heat transfer fluids.

Researchers for the use of nanofluids as advanced heat transfer fluid compared to conventional fluids used in heat transfer applications have been aimed at improving the thermophysical properties of nanofluids on magneto fields. Therefore, many parameters such as the size, concentration, shape, base fluid, $\mathrm{pH}$ effect and operating temperature of the nano particles used were examined.

In this study, information is given about the studies in the literature related to magneto hydrodynamic and the effects of thermophysical properties of the nanofluids on heat and flow characteristics are exemplified by a numerical study.
\end{abstract}

Keywords: Heat transfer, nanofluid, thermophysical properties, heat exchanger, CFD, MHD

DOI: $10.7176 /$ JETP/9-4-03

Publication date: April $30^{\text {th }} 2019$

\section{Introduction}

Convective heat transfer can be improved by changing the thermophysical properties of the fluid or flow geometry or boundary conditions. However, since air fluids such as air, water, oil and ethylene glycol used for convective heat transfer have very low thermal conductivity, they cannot meet the desired properties in today's technology. One of the techniques used to increase the heat transfer characteristics of heat transfer fluids is the addition of solid particles which have higher thermal conductivity than the fluids.

Recently, the use of nanofluid, which is a new type of suspension in which solid particles (metal, metal oxide, carbon nano tube) smaller than 100 nanometers are concerned, has been increased to use as heat transfer fluids. This increase is due to the fact that nanofluids have high thermal conductivity values, even at very small nanoparticle concentrations.

Copper, silver, copper oxide, titanium oxide and aluminum oxide are generally used as nanoparticles. Keblinski et al. (2002) stated that the significant increase in the heat conductivity of the nanofluids is due to the Brownian movement of the solid particles, the fluid stratification at the molecular level, the nature of the heat transfer mechanism and the nanoparticle accumulation in the liquid solid surface. The most important parameter of heat transfer in nanofluids is heat conduction. For heat transfer applications, research for nano fluids has been aimed at developing thermophysical properties. Many parameters such as particle size, particle concentration, particle type, mother fluid and operating temperature were examined.

Magneto hydrodynamic is a branch of science that examines the flow of electrified fluids (gases or plasmas in the form of ions) in electromagnetic fields. Since 1958, a lot of research on magneto hydrodynamics has been carried out in America and Europe; because, as in conventional thermal stations, hydro magnetism allows heat energy to be converted directly into electricity without undergoing mechanical energy. In addition, this conversion yields better efficiency than thermoelectric events.

Magnetic nanofluid (Ferrofluid) is a magnetic colloidal suspension consisting of base liquid and magnetic nanoparticles with a size range of 5-15 nm in diameter coated with a surfactant layer. Many industrial equipment, such as magneto hydrodynamic (MHD) generators, pumps and bearings are affected by the interaction between the electrically conducting fluid and a magnetic field. The behavior of the flow strongly depends on the orientation and intensity of the applied magnetics. The exerted magnetic field manipulates the suspended particles and rearranges their concentration in the fluid which strongly changes heat transfer characteristics of the flow.

The seminal study about MHD flows was conducted by Alfven who won the Nobel Prize for his work .Later, Hartmann did a unique investigation on this kind of flow in a channel. Afterwards, many researchers have emphasized this concept.

Kefayati (2015) demonstrated MHD mixed convection of non-Newtonian fluid. He presented new powerful method. 


\section{Development of Nanofluids}

The 'nanofluid' term is the suspended dispersed nanoparticles introduced by the researchers in the Argonne National laboratory and pointing to a two-phase mixture formed in the continuous fluid phase. Today, nanofluids are shown as new generation heat transfer fluids with improved heat transfer performance compared to pure liquids. The term "nanotechnology" was first mentioned in a 1974 article by Norio Taniguchi of Tokyo Science University. In this article, Taniguchi; "nanotechnology" consists of an atom or molecule with separation-joining-deformation processes.

Nanotechnology involves the control of substances in the range of about 1 to 100 nanometers and understanding their behavior. The term nano structured is simply not a liquid-solid mixture. It should contain some special requirements. These; stable suspension is the very low bulk of the nanoparticles (clustering) and the lack of chemical changes of the fluid. For this purpose; the formation of particulate agglomerates must be avoided in order to change the surface properties of the suspended particles in the fluid and to provide a stable suspension. Different types of surfactants can be used to ensure stability over the properties of the nanoparticles. The surfactants absorb the surface tension of water by absorbing them at the liquid-gas interface. They also absorb the liquid-liquid interface and reduce the tension between water and oil.

Metals ( $\mathrm{Ag}, \mathrm{Cu}, \mathrm{Fe}$ and $\mathrm{Au})$, metal oxides $\left(\mathrm{Al}_{2} \mathrm{O}_{3}, \mathrm{CuO}\right)$, nitrite ceramics and carbon nanotubes can be used in the production of nanofluids. Two basic techniques are used to produce nanofluids. These; two-step technique (top-down) and one-step (bottom-up) technique.

Nano fluids have superior properties than micro size metal particles compared to base fluids. The reasons for this are as follows:

a. Suspended nanoparticles increase the surface area and heat capacity of the fluid for heat transfer,

b. Suspended nanoparticles increase the effective thermal conductivity of the fluid,

c. The surface of the fluid and flow passage increases as a result of interactions and collisions between particles.

d. The turbulence of the fluid and the irregularity of the mixture increase,

e. The distribution of the nanoparticles reduces the gradient of the fluids transverse temperature (flattens the tendency).

Since 1999, the publications on nanofluids have increased. Fig. 1 shows the distribution of the number of publications according to years.

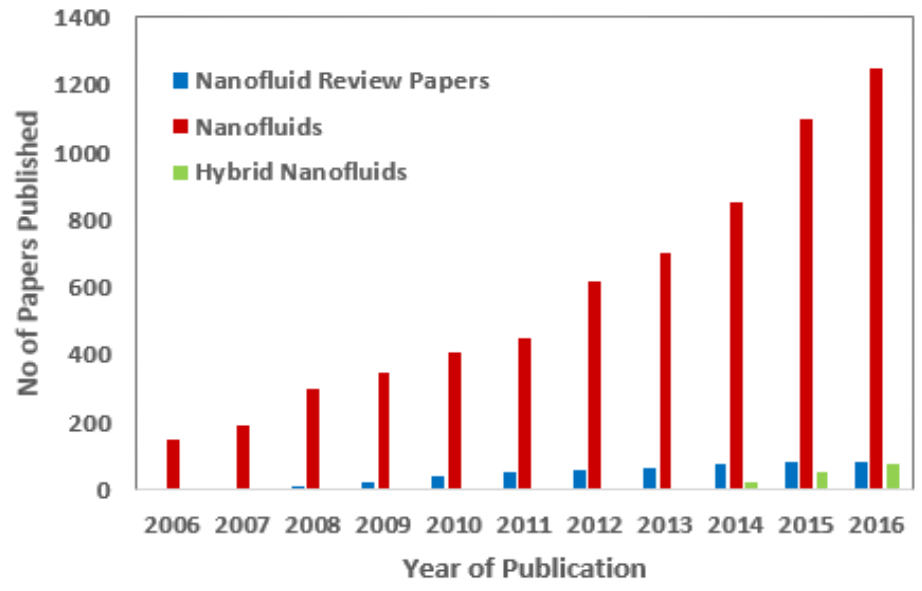

Figure 1.Distribution graph of nanofluid academic publications according to years

\section{Gains of Nanofluids}

In heat transfer applications, the most common research for nanofluids has been the development of thermal conductivity. Many parameters such as particle size, particle concentration, particle type, base fluid and operating temperature were examined.

The two most commonly used fluids in research are water and ethylene glycol. Tab.1 shows the general results of the thermal conductivity of the researchers. 
Table 1. Gains of thermal conductivity

\begin{tabular}{|c|c|c|c|c|}
\hline Author/Year & Nanofluid & Particle size (nm) & Concentration (vol\%) & Enhancement Ratio \\
\hline \multirow[t]{4}{*}{ Lee et al./1999 $9^{[40]}$} & $\mathrm{Al}_{2} \mathrm{O}_{3}$-water & 38,40 & $1,00-4,30$ & $1,03-1,10$ \\
\hline & CuO-water & 23,60 & $1,00-3,41$ & $1,03-1,12$ \\
\hline & $\mathrm{Al}_{2} \mathrm{O}_{3}$-ethylene glycol & 38,40 & $1,00-5,00$ & $1,03-1,18$ \\
\hline & CuO-ethylene glycol & 23,60 & $1,00-5,01$ & $1,05-1,23$ \\
\hline \multirow[t]{6}{*}{ Wang et al./1999[41] } & $\mathrm{Al}_{2} \mathrm{O}_{3}$-water & 28,00 & $0,19-1,59$ & $1,01-1,10$ \\
\hline & $\mathrm{CuO}$-water & 23,00 & & \\
\hline & $\mathrm{Al}_{2} \mathrm{O}_{3}$-ethylene glycol & 28,00 & $5,00-8,00$ & $1,25-1,41$ \\
\hline & CuO-ethylene glycol & 23,00 & $6,20-14,80$ & $1,24-1,54$ \\
\hline & $\mathrm{Al}_{2} \mathrm{O}_{3}$-engine oil & 28,00 & $2,25-7,40$ & $1,05-1,30$ \\
\hline & $\mathrm{Al}_{2} \mathrm{O}_{3}$-pump oil & 28,00 & $5,00-7,10$ & $1,13-1,20$ \\
\hline \multirow[t]{4}{*}{ Xie et al./2002 ${ }^{[26]}$} & SiC-water & 26 sphere & $0,78-4,18$ & $1,03-1,17$ \\
\hline & & 600 cylinder & $1,00-4,00$ & $1,06-1,24$ \\
\hline & SiC-ethylene glycol & 26 sphere & $0,89-3,50$ & $1,04-1,13$ \\
\hline & & 600 cylinder & $1,00-4,00$ & $1,06-1,23$ \\
\hline \multirow[t]{3}{*}{ Xie et al./2002 ${ }^{[48]}$} & $\mathrm{Al}_{2} \mathrm{O}_{3}$-water & 60,4 & 5,00 & 1,23 \\
\hline & $\mathrm{Al}_{2} \mathrm{O}_{3}$-ethylene glycol & 60,4 & 5,00 & 1,29 \\
\hline & Al2O3-pump oil & 60,4 & 5,00 & 1,38 \\
\hline \multirow[t]{4}{*}{ Das et al. $/ 2003^{[44]}$} & $\mathrm{CuO}$-water & & & \\
\hline & $\left(21^{\circ} \mathrm{C}\right)$ & 28,60 & $1,00-4,00$ & $1,07-1,14$ \\
\hline & $\left(36^{\circ} \mathrm{C}\right)$ & 28,60 & $1,00-4,01$ & $1,22-1,26$ \\
\hline & $\left(51^{\circ} \mathrm{C}\right)$ & 28,60 & $1,00-4,02$ & $1,29-1,36$ \\
\hline
\end{tabular}

Choi (1995), where the thermal capacity, density and viscosity of nanofluids remain constant; he pointed out that the heat transfer coefficient should be increased by increasing the flow rate or thermal conductivity of the fluid. Based on this; As a result of non-uniform thermal conductivity and viscosity distributions due to Brownian motions of nanoparticles, they concluded that heat transfer would be increased by decreasing the thermal boundary layer thickness. Tab. 2 shows the heat transfer improvements obtained by the researchers.

Table 2. Gains of heat transfer

\begin{tabular}{|c|c|c|c|c|}
\hline Author/Year & Nanofluid & Particle size (nm) & $\begin{array}{l}\text { Concentration } \\
(\text { vol \%) }\end{array}$ & $\begin{array}{c}\text { Enhancement } \\
\text { Ratio }\end{array}$ \\
\hline \multirow[t]{4}{*}{ Putra et al./2003[18] } & $\mathrm{Al}_{2} \mathrm{O}_{3}$-water & 131,20 & 1,00 & $0,85-1,02$ \\
\hline & $(\mathrm{L} / \mathrm{D}=0,5)$ & 131,20 & 4,00 & $0,70-0,85$ \\
\hline & $\mathrm{Al}_{2} \mathrm{O}_{3}$-water & 131,20 & 1,00 & $0,87-1,04$ \\
\hline & $(\mathrm{L} / \mathrm{D}=1,0)$ & 131,20 & 1,00 & $0,63-0,82$ \\
\hline \multirow[t]{7}{*}{ Xuan et al./2003[19] } & CuO-water & $<100$ & 0,30 & $0,99-1,05$ \\
\hline & & $<100$ & 0,50 & $1,01-1,08$ \\
\hline & & $<100$ & 0,80 & $1,07-1,13$ \\
\hline & & $<100$ & 1,00 & $1,13-1,15$ \\
\hline & & $<100$ & 1,20 & $1,14-1,21$ \\
\hline & & $<100$ & 1,50 & $1,23-1,27$ \\
\hline & & $<100$ & 2,00 & $1,25-1,35$ \\
\hline \multirow[t]{6}{*}{ Wen et al./2004 [11] } & $\mathrm{Al}_{2} \mathrm{O}_{3}$-water & 42 & 0,60 & $1,04-1,12$ \\
\hline & $(\mathrm{x} / \mathrm{D}=63)$ & 42 & 1,00 & $1,09-1,22$ \\
\hline & & 42 & 1,60 & $1,25-1,38$ \\
\hline & $\mathrm{Al}_{2} \mathrm{O}_{3}$-water & 42 & 0,60 & $1,10-1,20$ \\
\hline & $(x / D=116)$ & 42 & 1,00 & $1,12-1,20$ \\
\hline & & 42 & 1,60 & $1,26-1,35$ \\
\hline \multirow[t]{2}{*}{ Yang et al./2005 [24] } & $\begin{array}{l}\text { Graphite-transmission Fluid } \\
\left(50^{\circ} \mathrm{C}\right)\end{array}$ & $1000-2000 \times 2$ & 0,77 & $0,97-1,02$ \\
\hline & $\begin{array}{l}\text { Graphite-transmission Fluid } \\
\left(70^{\circ} \mathrm{C}\right)\end{array}$ & $1000-2000 \times 2$ & 0,77 & $0,97-1,03$ \\
\hline \multirow[t]{3}{*}{ Choi et al./2008[55] } & $\mathrm{Al}_{2} \mathrm{O}_{3}$ (sphere)-pure oil & 13 & 0,5 & $1,01-1,03$ \\
\hline & & $2 \times 20-200$ & 0,5 & $1,14-1,17$ \\
\hline & $\begin{array}{l}\mathrm{Al}_{2} \mathrm{O}_{3} \text { (fiber)-pure oil } \\
\mathrm{AIN} \text {-pure oil }\end{array}$ & 50 & 05 & 12420 \\
\hline
\end{tabular}




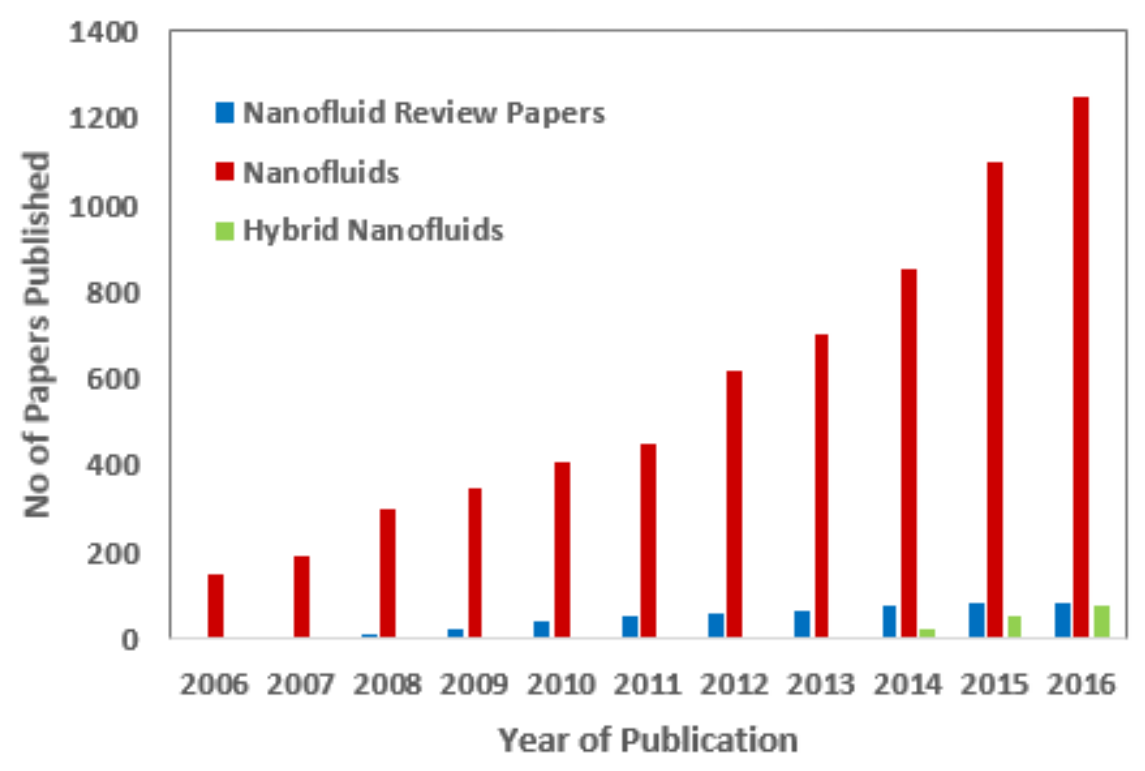

\subsection{Parameters Effecting the Gains obtained From Nanofluids}

\subsubsection{Particle Volume Ratio}

The effect of the experimental particle volume ratio of $\mathrm{Al}_{2} \mathrm{O}_{3}$-water nanofluid on the thermal conductivity coefficient is shown in Fig. 2.
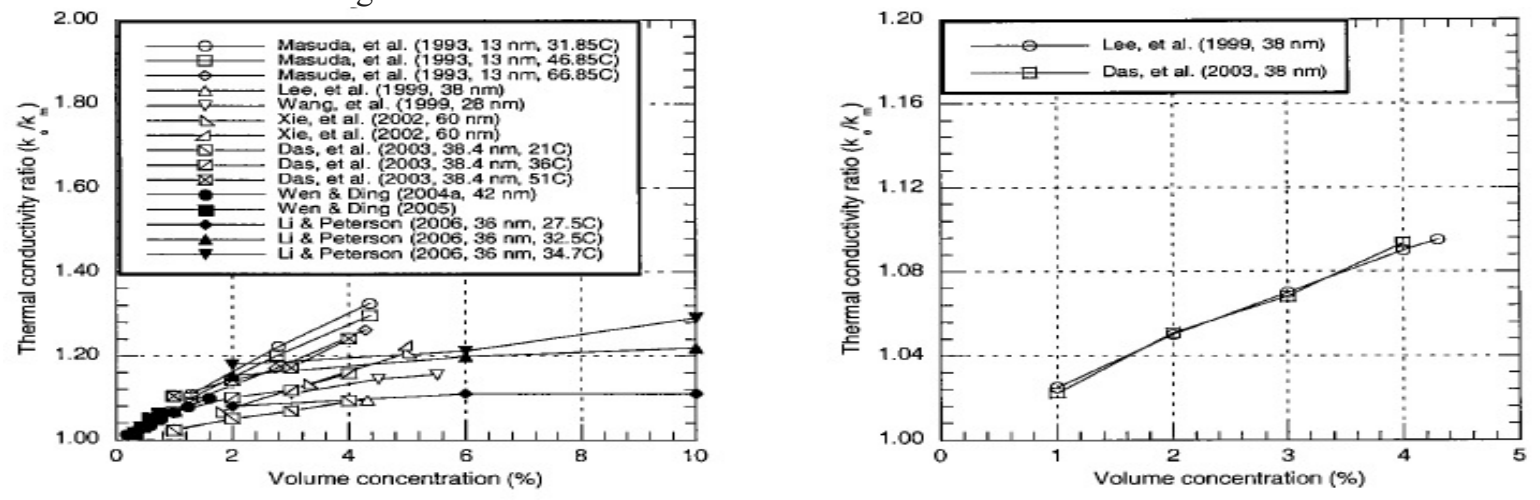

\subsubsection{The Effect of Particle Material}

Figure 2. $\mathrm{Al}_{2} \mathrm{O}_{3}$-water particle volume ratio effect

Many studies have shown that the effect of particulate matter on thermal conductivity of nanofluids is a very important parameter. The experimental results of different particles with water and ethylene glycol as base fluid are presented in Fig. 3.
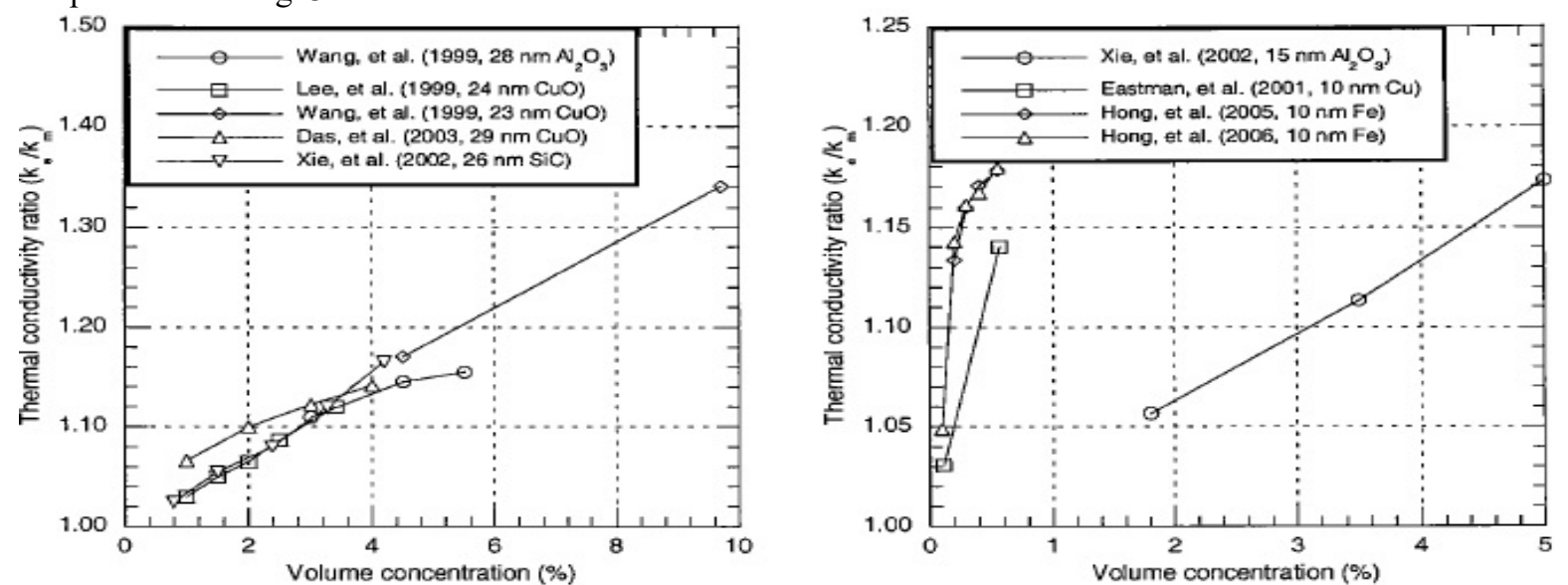

Figure 3. Different particle usage effects based on water (left) and ethylene glycol (right)

\subsubsection{Base Fluid}

According to the traditional thermal conductivity models such as the Maxwell model, the thermal conductivity 
ratio increases $\left(\mathrm{k}_{\mathrm{nf}} / \mathrm{k}_{\mathrm{f}}\right)$ by decreasing the thermal conductivity of the base fluid forming the mixture. The lowest rate was obtained when using pump fluid. The effect of different base fluids and $\mathrm{Al}_{2} \mathrm{O}_{3}$ nanofluids is presented in Fig. 4.

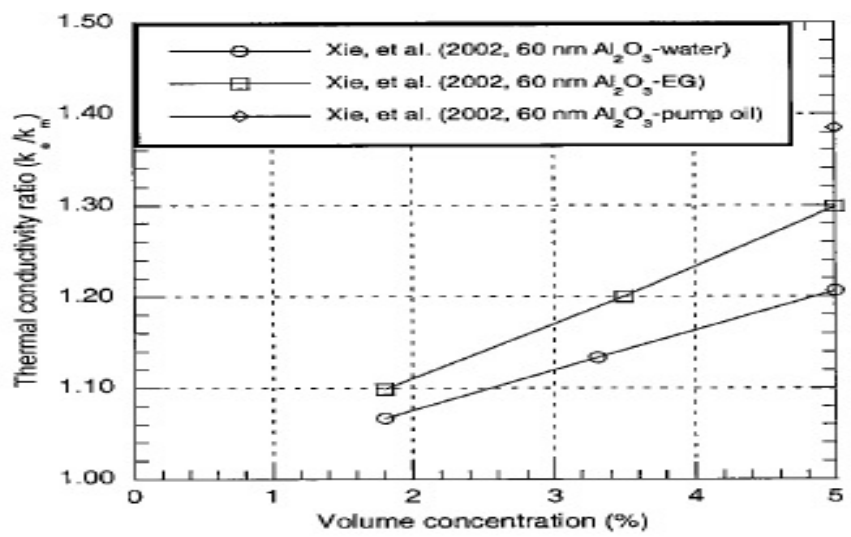

Figure 4. $\mathrm{Al}_{2} \mathrm{O}_{3}$ different base fluid effect

\subsubsection{Particle Size}

Chopkar et al. (2007) investigated the effect of particle size on thermal conductivity using water and ethylene glycol with $\mathrm{Al}_{2} \mathrm{Cu}$ and $\mathrm{Ag}_{2} \mathrm{Al}$ nanoparticles. The experimental results of particle size effect of water based $\mathrm{CuO}$ and $\mathrm{Al}_{2} \mathrm{O}_{3}$ nanofluids are presented in Fig. 5 .
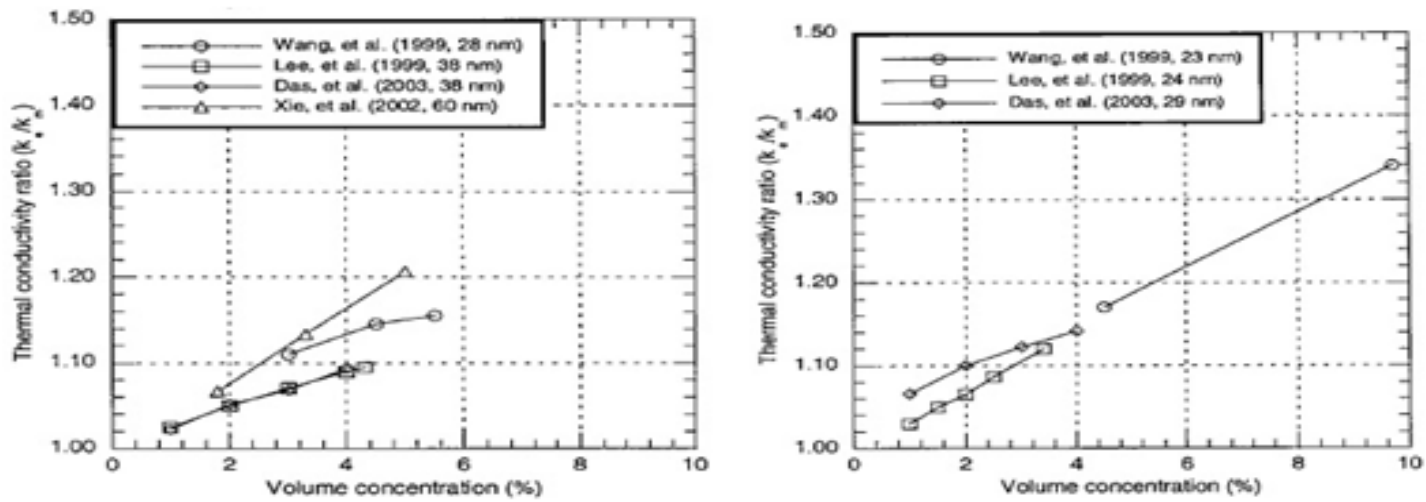

Figure 5. $\mathrm{Al}_{2} \mathrm{O}_{3}$-water (left) and $\mathrm{CuO}$-water (right) particle size effect

\subsubsection{Particle Shape}

In studies with nanofluids, two types of particle shape are generally studied. These; spherical and cylindrical particles. The particle shape effect of $\mathrm{SiC}$-ethylene glycol and $\mathrm{TiO}_{2}$-water nanofluids is presented in Fig. 6.
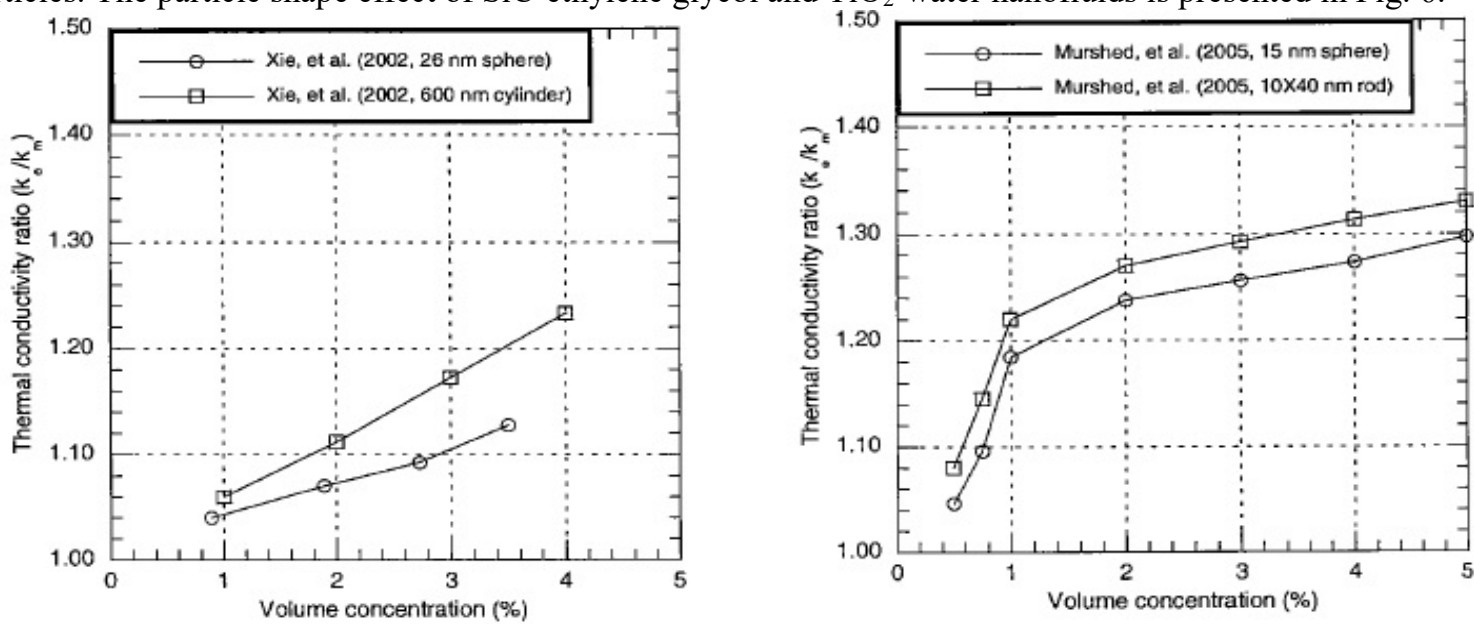

\subsubsection{The Effect of Temperature}

In conventional suspensions of solid particles (sizes in millimeters or micrometers), while the thermal conductivity of the mixture depends on temperature, this temperature also depends on the temperature of the base fluid and the solid particles. This has a great effect on the thermal conductivity changes of temperature and nanofluids. Fig. 7 
shows the water-based $\mathrm{Al}_{2} \mathrm{O}_{3}$ and $\mathrm{CuO}$ nanofluids temperature effect.
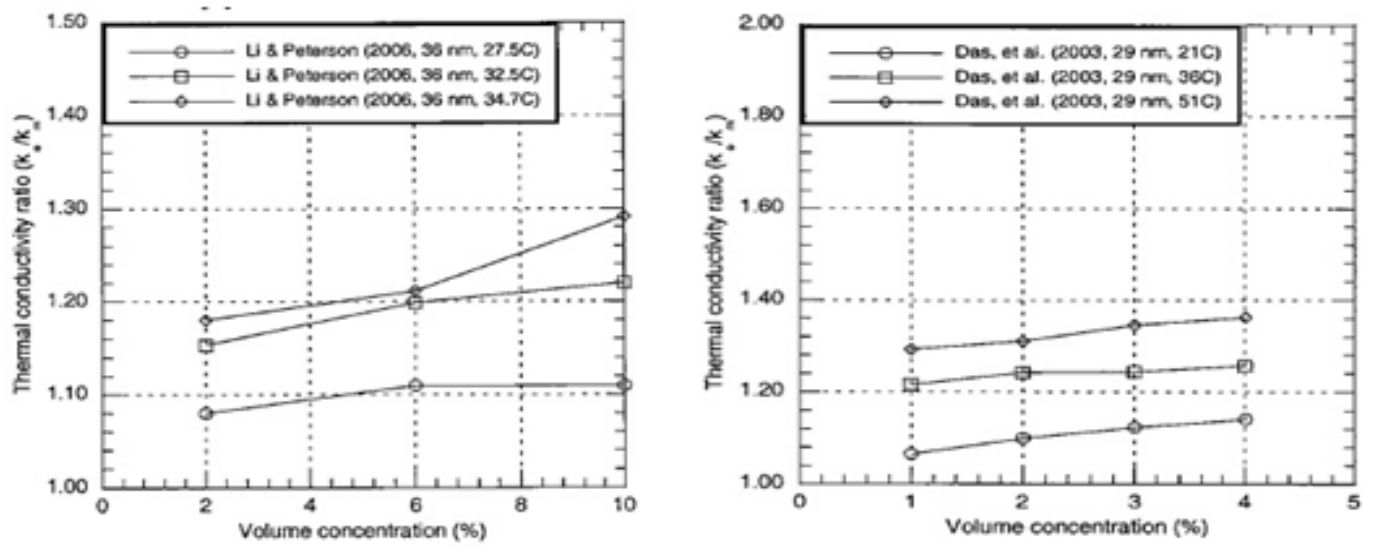

Figure 7. $\mathrm{Al}_{2} \mathrm{O}_{3}$-water (left) and $\mathrm{CuO}$-water (right) temperature effect

\section{Thermophysical Properties of Nanofluids}

\subsection{Density}

The density of nanofluids can be calculated by the Pak and Cho equation, which is derived from the physics principle. $\phi$ is volumetric ratios of solid particles, while the subindices $\mathrm{nf}, \mathrm{f}$ and $\mathrm{p}$ represent nanofluids, base fluid and solid particles, respectively. Pak and Cho (1998) have demonstrated the accuracy of this equation experimentally.

$$
\begin{gathered}
\rho=\left(\frac{m}{V}\right)_{n f} \\
\rho_{n f}=(1-\phi) \rho_{f}+\phi \rho_{p}
\end{gathered}
$$

\subsection{Specific Heat}

Xuan and Roetzel (2000) equations are used in the calculation of the specific heat of nanofluids

$$
\left(\rho C_{p}\right)_{n f}=(1-\phi)\left(\rho C_{p}\right)_{f}+\phi\left(\rho C_{p}\right)_{p}
$$

\subsection{Viscosity}

Viscosity of nanofluid is an important parameter in practical applications and directly affects the pressure drop in forced transport. In order to make the nanofluids usable in practical applications, the extent of viscosity increase of nanofluids compared to pure fluids should be well investigated. Studies on viscosity of nanofluids are limited in the literature.

\subsubsection{Studies on Viscosity}

The viscosity of nanofluids depends on many parameters: particle volume ratio, particle size, temperature. The viscosity increases as the particle volume ratio increases and this is demonstrated in many studies (Murshed et al., Nguyen et al., Kulkarni et al., Chen et al.).Some correlations obtained as a result of studies on viscosity are presented in Tab. 3. 
Table 3. Viscosity correlations

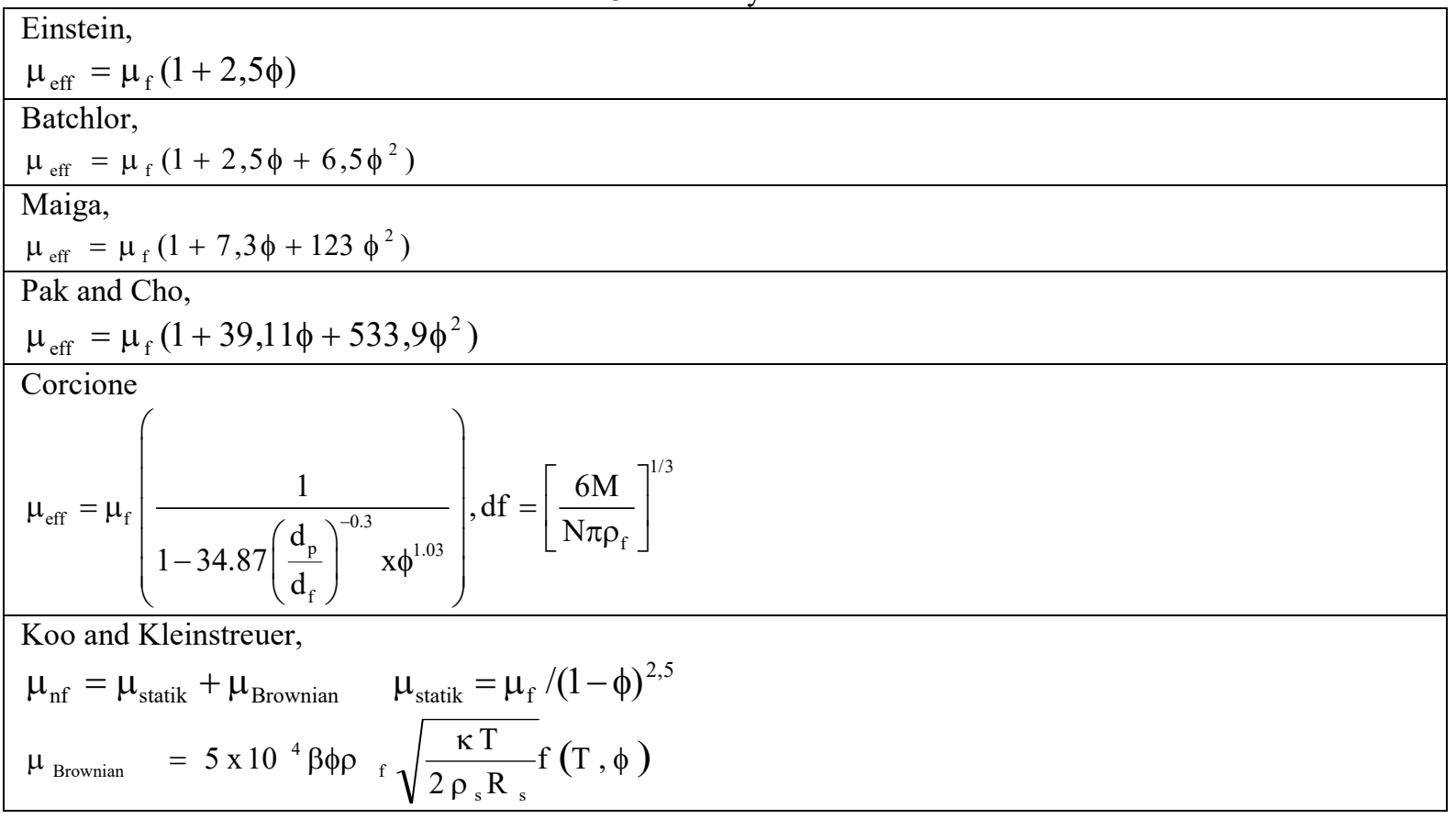

\subsection{Thermal Conductivity}

Many studies on thermal conductivity are available in the literature. Thermal conductivity indicates the heat conducting capacity of a substance and depends on many factors.

\subsubsection{Studies on Thermal Conductivity}

Numerous experimental equations have been developed to estimate the thermal conductivity of nanofluids (Maxwell, Hamilton, Mushed and Yu.).Some thermal conductivity correlations obtained as a result of the studies are presented in Tab. 4.

Table 4. Thermal conductivity correlations

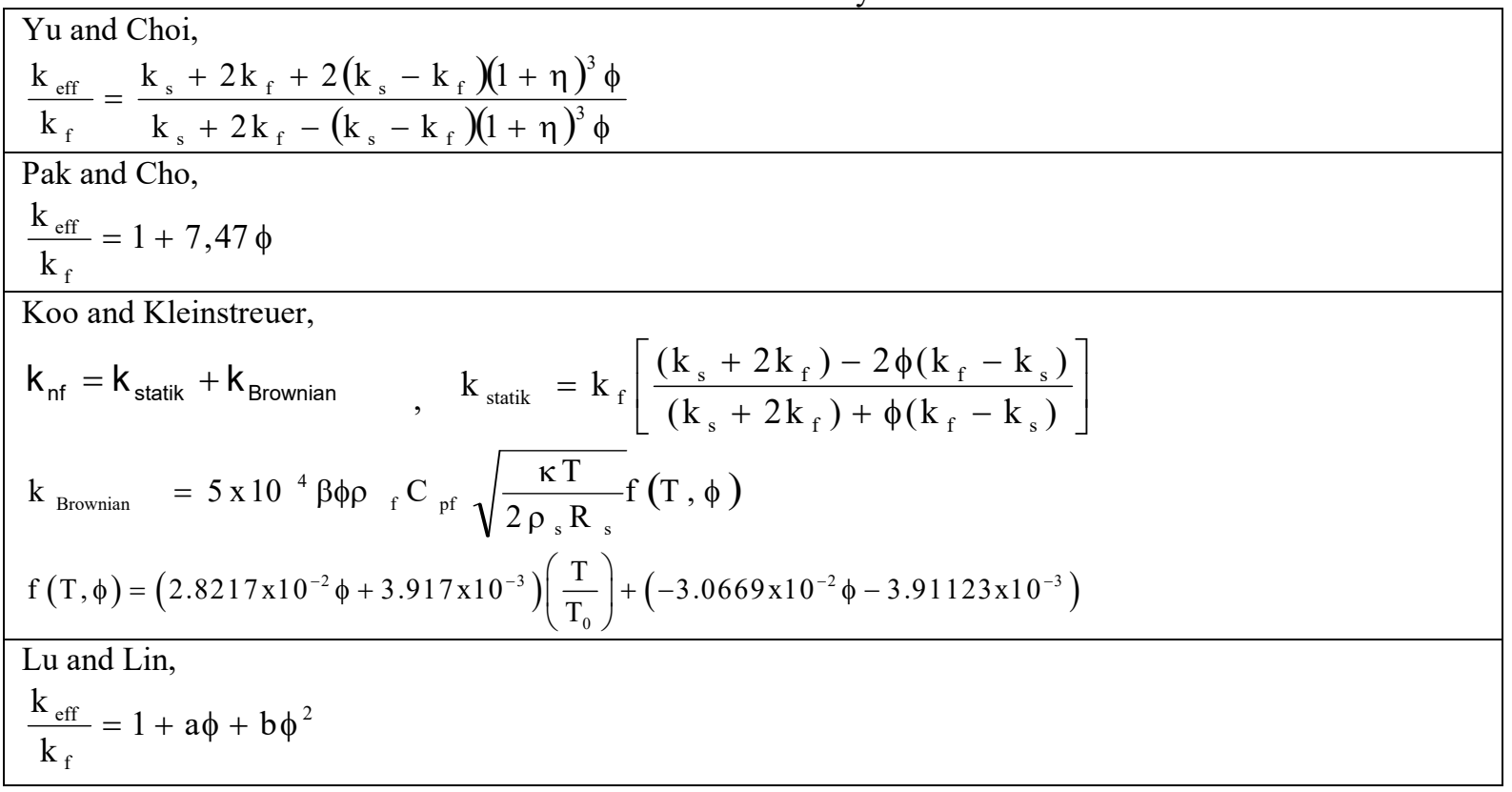

\subsection{Coefficient of Thermal Expansion}

The thermal expansion coefficient of nanofluids can be written in terms of the volume ratio of the nanoparticles. As a result of the studies, some correlations obtained at different temperature and volume concentration ranges and for different particles are presented in Tab. 5. 
Table 5. Thermal expansion correlations

\begin{tabular}{lccc}
\hline Type of particles & $\boldsymbol{\beta}$ & Concentration (\%) & Temperature (K) \\
\hline $\mathrm{Al}_{2} \mathrm{O}_{3}$ & $8.447(100 \phi)-1.07304$ & $1 \% \leq \phi \leq 10 \%$ & $298 \leq \mathrm{T} \leq 363$ \\
$\mathrm{CuO}$ & $9.881(100 \phi)-0.9446$ & $1 \% \leq \phi \leq 6 \%$ & $298 \leq \mathrm{T} \leq 363$ \\
$\mathrm{SiO}_{2}$ & $1.9526(100 \phi)-1.4594$ & $1 \% \leq \phi \leq 6 \%$ & $298 \leq \mathrm{T} \leq 363$ \\
$\mathrm{ZnO}$ & $8,4407(100 \phi)-1,07304$ & $1 \% \leq \phi \leq 6 \%$ & $298 \leq \mathrm{T} \leq 363$ \\
\hline
\end{tabular}

\section{Numerical Study}

A numerical study is presented in this section. Ogut and Dilki (2018) investigated numerically the fully developed turbulent flow and heat transfer behaviors of the water-based nanofluid in the corrugated trapezoidal plate heat exchanger .In the analysis, the effects of $\mathrm{SiO}_{2}$ nanoparticles with different volume fractions $(\phi=0 \%-4 \%)$, different numbers of $\operatorname{Re}(6000-20000)$ and diameter $\mathrm{d}=20 \mathrm{~nm}$ were examined under constant heat flux $\left(6 \mathrm{~kW} / \mathrm{m}^{2}\right)$. Viscosity was obtained by Corcione [3] and thermal conductivity was obtained by Koo and Kleinstreuer correlation [9]. Viscosity;

Thermal conductivity;

$$
\mu_{e f f}=\mu_{f}\left(\frac{1}{1-34.87\left(\frac{d_{p}}{d_{f}}\right)^{-0.3} x \phi^{1.03}}\right), d f=\left[\frac{6 M}{N \pi \rho_{f}}\right]^{1 / 3}
$$

$$
\begin{gathered}
k_{\text {eff }}=k_{\text {statik }}+k_{\text {Brownian }} \\
k_{s}=k_{f}\left[\frac{\left(k_{p}+2 k_{f}\right)-2 \phi\left(k_{f}-k_{p}\right)}{\left(k_{p}+2 k_{f}\right)+\phi\left(k_{f}-k_{p}\right)}\right] \\
k_{\text {Brownian }}=5^{*} 10^{4} \beta \phi \rho_{f} C_{p, f} \sqrt{\frac{\kappa T}{2 \rho_{p} d_{p}}} f(T, \phi) \\
\beta=1.9526(100 \phi)^{-1.4594} \\
f(T, \phi)=\left(2.8217 \times 10^{-2} \phi+3.917 \times 10^{-3}\right)\left(\frac{T}{T_{0}}\right)+\left(-3.0669 \times 10^{-2} \phi-3.91123 \times 10^{-3}\right)
\end{gathered}
$$

In Fig. 8, the base fluid water and $\mathrm{SiO}_{2}$-water nanofluids with volume fraction $\phi=0.04$ show the same number of $\mathrm{Nu}$ numbers on the left and the pressure drop changes on the right. When the average Nusselt number is compared with the base fluid water and the nanofluid with $4 \%$ solid volume ratio, it is seen that the nanofluid has higher values. The flow rate increases with Reynolds number increasing the pressure drop. 

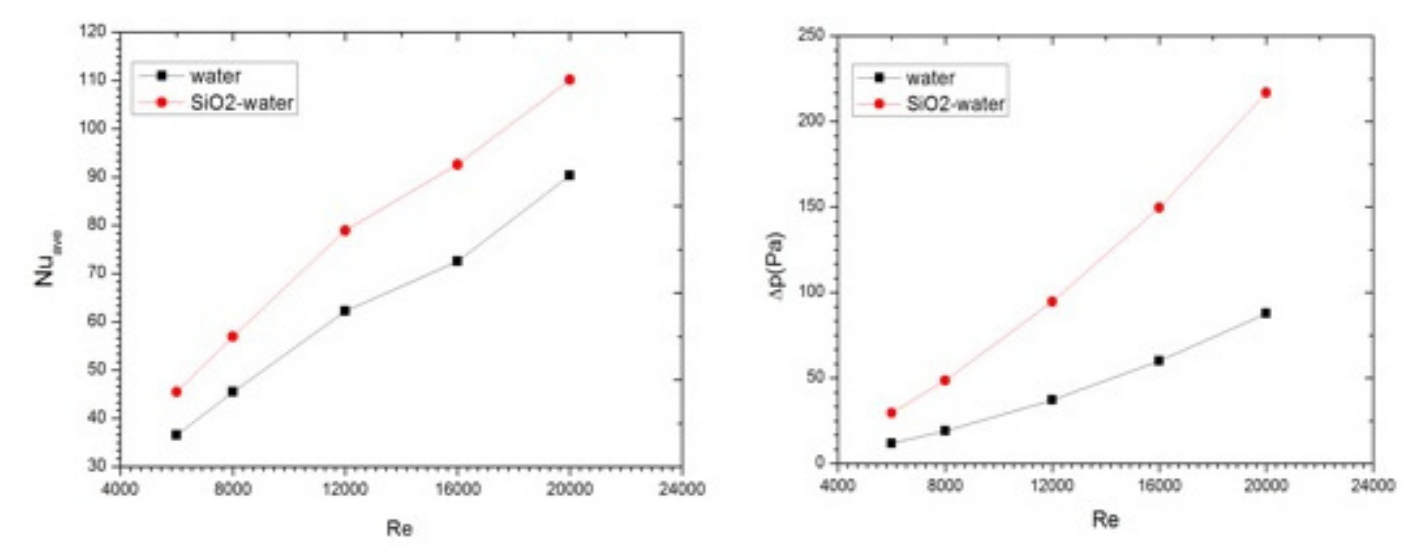

Figure 8. Effect of base fluid water and $\mathrm{SiO} 2$-water nanofluid with different Reynolds numbers on the average Nusselt number (left) and the pressure drops (right) volume fraction $\phi=0.04$.

Fig. 9 shows the different number of Re and nanofluid in different volume ratios on the left and the number of Nusselt changes in the right and pressure drop on the right. Accordingly, both the average Nusselt number and the pressure drop increase with increasing Reynolds number and solid volume ratio.
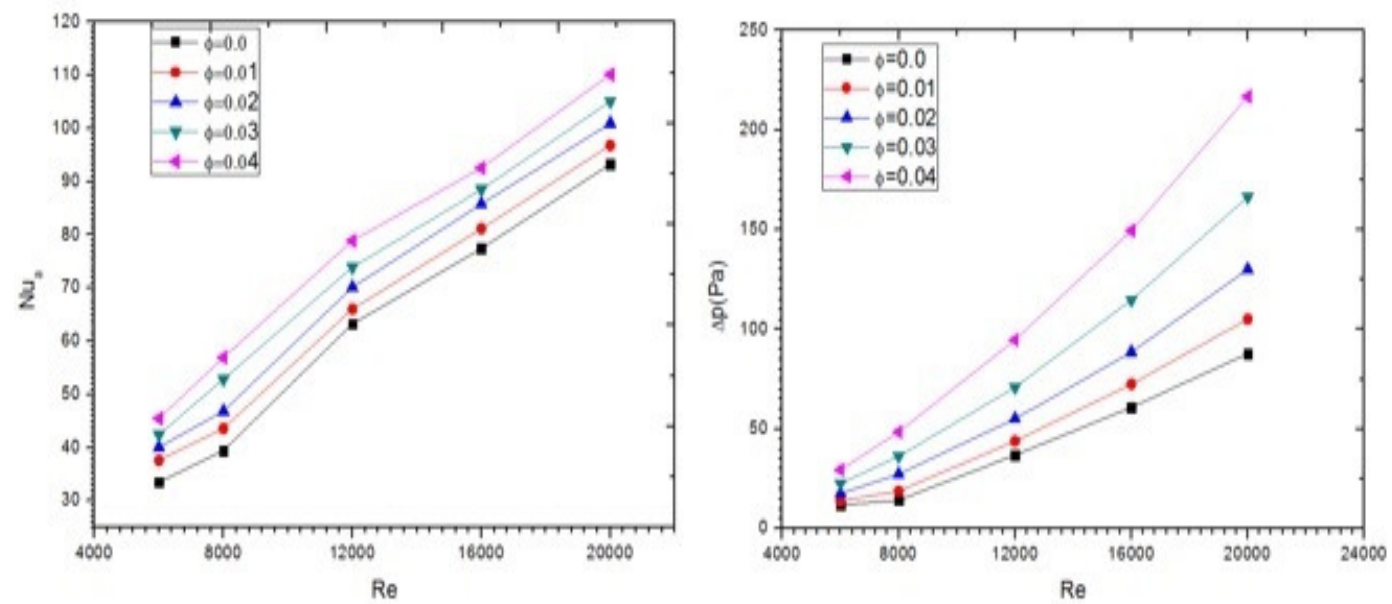

Figure 9. Effect of $\mathrm{SiO}_{2}$-water nanofluid on the average Nusselt number (left) and the pressure drops (right) at different Reynolds number and volume fractions

\section{Conclusions}

Although a generalization has not been made, the comments made on nanofluids so far can be summarized as follows:

1. The effective viscosity of nanofluids increases with increasing volume ratio and decreases with increasing temperature.

2. Effective thermal conductivity of nanofluids increases with increasing temperature and volume ratio and decreases with increasing particle diameter.

3. Classical models can be used to calculate the thermal conductivity and viscosity of nanofluids at room temperature, low volume ratios. However, at other temperatures, these models are not suitable for the calculation of thermal conductivity.

4. The viscosity of nanofluids plays a key role in determining the heat transfer characteristics.

5. Many researchers have developed their thermal conductivity modeling on the effects of Brownian motion of nanoparticles. The main argument here is associated with large collisions that occur between the particles during random movements. This enables heat transfer between the colliding particles. In the Brownian movement, it is also believed that the nano-sized fluid produces micro-transport. As the random movement with small-sized nanoparticles increases and the micro-convection effect will become dominant, thermal conductivity will increase. Brownian speed increases with increasing temperature and shrinking particle size.

6. As the thickness of the nano layer between the nanoparticles and the fluid increases, the thermal conductivity also increases.

7. While some clustering increases the thermal conductivity gain, excessive clustering has an adverse effect. Therefore, the optimum level of clustering should be determined for maximum thermal conductivity gain. 


\section{References}

Brinkman HC. The viscosity of concentrated suspensions and solution. Journal of Chemical Physics 1952; 20:571-81.

Choi, S.U.S., Enhancing thermal conductivity of fluids with nanoparticles, Develop. Appl. Non Newtonian Flows, 1995; 99-106.

Corcione M. Rayleigh-Bénard convection heat transfer in nanoparticle suspensions. International Journal of Heat and Fluid Flow 2011; 32:65-77.

Chopkar M, Kumar S, Bhandari D R, Das P K and Manna I Mater. Sci. Eng. 2007; B139:141-148.

Einstein A. Eine neue bestimmung der molekuldimensionen. Annalen der Physik, Leipzig 1906; 19:289-306.

Hamilton RL, Crosser OK. Thermal conductivity of heterogeneous twocom- ponent systems. I\&EC Fundamentals 1962; 1(3); 187-91.

Keblinski, P., Philpot, S.R., Choi, S.U.S. and Eastman, J.A. , Mechanisms of Heat Flow in Suspensions of Nanosized Particles (nanofluids), Int. J. Heat Mass Transfer, 2002;45, 855-863.

G.H.R. Kefayati, FDLBM simulation of magnetic field effect on mixed convection in a two sided lid-driven cavity filled with non-Newtonian nanofluid, Powder Technology 280 (2015) 135-153.

Koo J, Kleinstreuer C. A new thermal conductivity model for nanofluids. Journal of Nanoparticle Research 2004; 6(6):577-88.

M. Pantzali, A. Mouza, S. Paras, Investigating the efficacy of nanofluids as coolants in plate heat exchangers (PHE), Chem. Eng. Sci. 2009; 64, 3290-3300.

Ogut, E, Dilki S. Investigation of Flow and Heat Transfer Characteristics of Nanofluids in Corrugated Trapezoidal Plate Heat Exchanger, 4th Anatolian Energy Symposium with International Participation, AES 2018;10831092.

Pak BC, Cho YI. Hydrodynamic and heat transfer study of dispersed fluids with submicron metallic oxide particles. Experimental Heat Transfer 1998; 11-15.

P. Naphon, Laminar convective heat transfer and pressure drop in the corrugated channels, Int. Commun. Heat Mass Transfer 2007; 34, 62-71.

Xie, H.; Wang, J.; Xi, T.; Liu, Y.; Ai, F.; Wu, Q. Thermal conductivity enhancement of suspensions containing nanosized alumina particles. J. Appl. Phys. 2002, 91, 4568-4572.

Xue QZ. Model for thermal conductivity of carbon nanotube-based compo- sites. Physica B: Condensed Matter 2005; 368(1-4):302-7.

Xuan, Y.M. and Roetzel, W. Conceptions for Heat Transfer Correlation of Nanofluids. International Journal of Heat and Mass Transfer 2000; 43: 3701-3707.

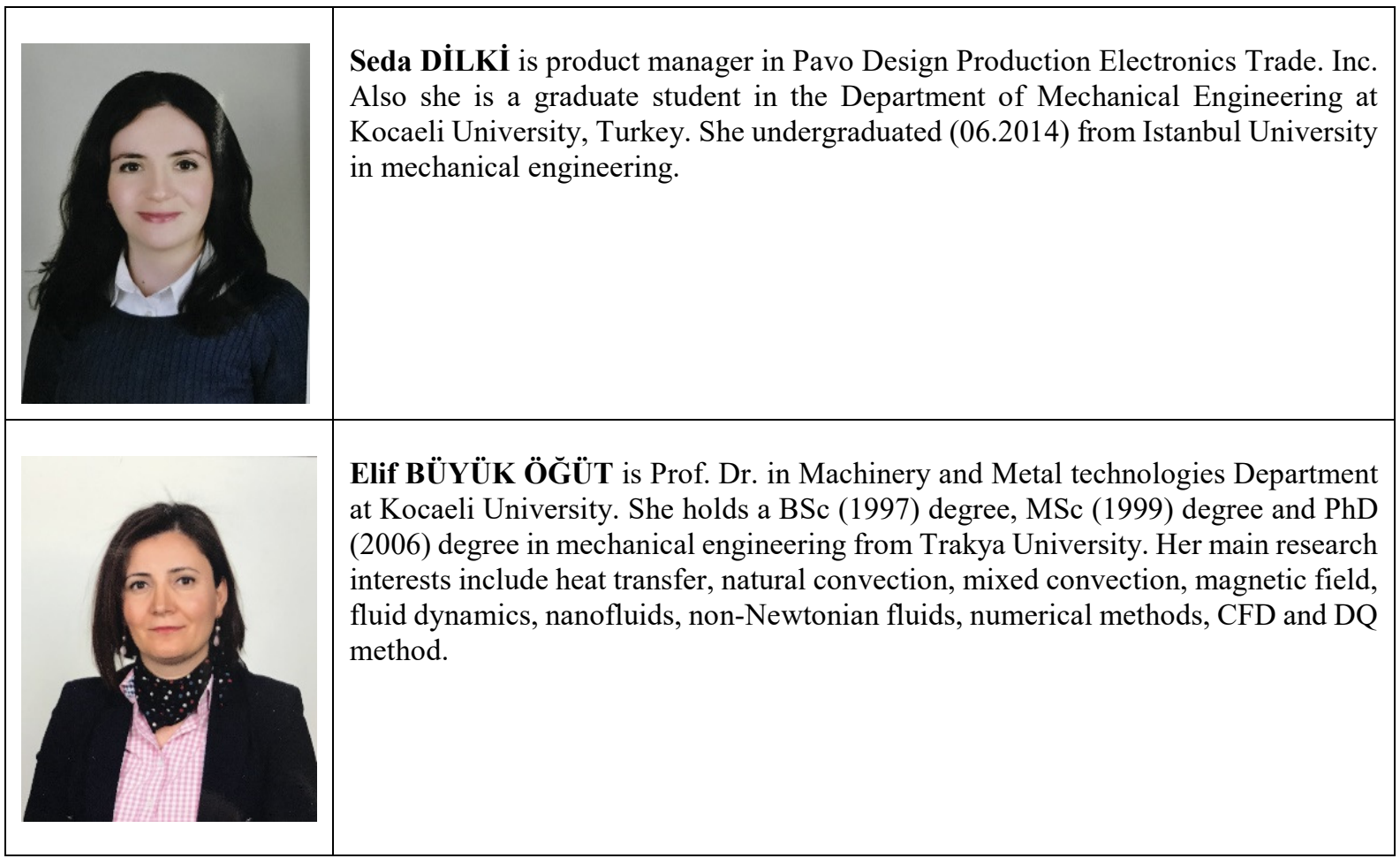

